\title{
Protein transport into peroxisomes: knowns and unknowns
}

Tânia Francisco ${ }^{1,2 \#}$, Tony A. Rodrigues ${ }^{1,2,3 \#}$, Ana F. Dias ${ }^{1,2,3}$, Aurora Barros-Barbosa ${ }^{1,2}$, Diana Bicho $^{1,2}$, Jorge E. Azevedo ${ }^{1,2,3, *}$

${ }^{1}$ Instituto de Investigação e Inovação em Saúde (i3S), Universidade do Porto, Rua Alfredo Allen, 208, 4200-135 Porto, Portugal

${ }^{2}$ Instituto de Biologia Molecular e Celular (IBMC), Universidade do Porto, Rua Alfredo Allen, 208, 4200-135 Porto, Portugal

${ }^{3}$ Instituto de Ciências Biomédicas de Abel Salazar (ICBAS), Universidade do Porto, Rua de Jorge Viterbo Ferreira, 228, 4050-313 Porto, Portugal

\# These authors contributed equally to this work.

* Corresponding author: jazevedo@ibmc.up.pt

Keywords: Peroxisomes, Peroxisomal import machinery, Protein translocation, Protein import, PEX5, PEX7.

Tânia Francisco; e-mail: taniaf@ibmc.up.pt

Tony A. Rodrigues; e-mail: tonyr@ibmc.up.pt

Ana F. Dias; e-mail: ana.dias@ibmc.up.pt

Aurora Barros-Barbosa; e-mail: aurora.barbosa@i3s.up.pt

Diana Bicho; e-mail: diana.bicho@i3s.up.pt

Jorge E. Azevedo; e-mail: jazevedo@ibmc.up.pt, telephone: +351 220408800

This is the peer reviewed version of the following article: Francisco, T., Rodrigues, T.A., Dias, A.F., Barros-Barbosa, A., Bicho, D. and Azevedo, J. E. (2017), Protein transport into peroxisomes: Knowns and unknowns. BioEssays, 39: 1700047, which has been published in final form at https://doi.org/10.1002/bies.201700047. This article may be used for non-commercial purposes in accordance with Wiley Terms and Conditions for Use of Self-Archived Versions. 


\begin{abstract}
Peroxisomal matrix proteins are synthesized on cytosolic ribosomes and rapidly transported into the organelle by a complex machinery. The data gathered in recent years suggest that this machinery operates through a syringe-like mechanism, in which the shuttling receptor PEX5 - the "plunger" - pushes a newly synthesized protein all the way through a peroxisomal transmembrane protein complex - the "barrel" - into the matrix of the organelle. Notably, insertion of cargo-loaded receptor into the "barrel" is an ATPindependent process, whereas extraction of the receptor back into the cytosol requires its monoubiquitination and the action of ATP-dependent mechanoenzymes. Here we review the main data behind this model.
\end{abstract}

\begin{abstract}
Abbreviations
AAA, ATPases associated with diverse cellular activities; DTM, docking/translocation module; DUB, deubiquitinating enzyme; GSH, glutathione; PIM, peroxisomal matrix protein import machinery; PTS, peroxisomal targeting sequence; REM, receptor export module; RING, really interesting new gene; TPR, tetratricopeptide repeats.
\end{abstract}

\title{
Introduction
}

Peroxisomes are single membrane-bound organelles found in almost all eukaryotic organisms [1]. In mammals, they have a relatively simple protein composition, harboring approximately 100 different proteins [2-4]. Despite their structural and functional simplicity, peroxisomes are of vital importance for human health and development, as underlined by a group of genetic diseases, the peroxisomal biogenesis disorders, in which peroxisomes are partially or even completely defective $[5,6]$. These disorders are caused by mutations in genes encoding peroxins, proteins specifically involved in peroxisome biogenesis [5-8]. There are 16 such proteins in mammals. Three are involved in peroxisome proliferation (reviewed in $[9,10]$ ). A set of three others is required for peroxisome membrane biogenesis (reviewed in $[11,12])$. The remaining 10 peroxins, together with a few additional components, comprise the peroxisomal matrix protein import machinery (PIM), the topic of this essay.

Peroxisomal matrix proteins are transported into the organelle within a few minutes after synthesis in the cytosol [13]. Their correct sorting depends on peroxisomal targeting 
sequences (PTSs), small domains in their primary structure that are recognized by shuttling receptors [14-17]. There are two kinds of targeting sequences, the so-called PTS type 1 and 2 (PTS1 and PTS2, respectively; see Fig. 1a for details). PTS1 proteins are transported to the peroxisome by the shuttling receptor PEX5 in all organisms studied up to now [17], whereas PTS2 proteins are delivered to the organelle by a protein complex comprising PEX5 and PEX7 in mammals, plants and many other organisms [14] or PEX7 and a PEX5-like peroxin in yeasts and fungi [14, 18-20] (see Fig. 1a).

PEX5 comprises two major domains (see Fig. 1b). One, encompassing its C-terminal half, consists of two interacting sets of three tetratricopeptide repeats (TPR) which provide the binding site for the PTS1 [21-23]. The other, encompassing its N-terminal half, is an intrinsically disordered domain [24] and harbors a series of short motifs which mediate the interaction of PEX5 with other peroxins [25-27]. In mammals, plants and many other organisms, one of these peroxins is PEX7, a 40-kDa WD-repeat protein that similarly to PEX5 displays a partially cytosolic, partially peroxisomal localization in vivo $[16,28]$. PEX7 interacts directly with the PTS2 [29-32] and functions as an ancillary factor of PEX5 (or yeasts/fungi PEX5-like peroxins) in the transport of PTS2 proteins to the peroxisome $[19,20,33,34]$.

\section{PEX5 as a holdase-like protein}

One of the most remarkable properties of the PIM is its capacity to accept already oligomerized proteins as substrates (reviewed in [35, 36]). Indeed, several studies have shown that when two interacting proteins are co-expressed in the same cell, the existence of a PTS in one of those proteins is sufficient to ensure a peroxisomal localization for at least a fraction of the other protein [37-39]. Those studies led to two conclusions. The first, which remains undisputed and is of major importance to understand the mechanism of the PIM, was that newly synthesized peroxisomal proteins do not have to be unfolded to be translocated across the organelle membrane [37-39]. The second was that most if not all peroxisomal proteins are imported into the organelle only after oligomerization in the cytosol [35, 36], a generalization that is probably incorrect. Indeed, a growing number of observations suggest that many peroxisomal matrix proteins that are oligomeric in their native state actually arrive at the organelle matrix as monomers (reviewed in [40]). The reason for this does not seem to be simply a kinetic property of the protein transport 
system, with import of newly synthesized proteins occurring faster than their oligomerization in the cytosol. Rather, recent data suggest that there is an active mechanism that maintains newly synthesized proteins in a monomeric state in the cytosol. Indeed, it was found that PEX5 binds the monomeric versions of several peroxisomal enzymes strongly inhibiting their oligomerization [40-42]. This, together with the fact that the cytosolic PEX5 concentration is probably large enough to bind all newly synthesized proteins that are en route to the organelle matrix, led to the proposal that PEX5 is also a chaperone keeping peroxisomal proteins in a near-native monomeric conformation thus blocking premature or unspecific interactions [42].

Interestingly, an analysis of the PEX5-catalase interaction revealed that the $\mathrm{N}$-terminal half of PEX5 is required for its holdase-like activity [42]. Actually, this domain alone inhibits catalase oligomerization, albeit less potently than the full-length protein. This, together with data showing that the N-terminal half of PEX5 from several organisms interacts with at least some cargo proteins [43, 44] suggests that this domain of PEX5 enfolds the cargo protein, thus shielding it from other proteins. It is also possible that a segment(s) of the intrinsically disordered N-terminal half of PEX5 acts as an entropic bristle [45], excluding other proteins from the vicinity of the cargo protein with which it interacts.

\section{Activating the "plunger" - the auto-regulatory mechanism of PEX5}

As described below, PEX5 becomes transiently inserted into a peroxisomal transmembrane protein complex - the Docking/Translocation Module (DTM) - at a certain stage of the protein transport cycle. Although none of the steps leading to that stage require energy from NTP hydrolysis, the subsequent extraction of PEX5 from the DTM does consume ATP [46]. Thus, it is not surprising that the PIM avoids futile energy-costing cycles by ensuring that only PEX5 molecules carrying a cargo protein have access to the DTM $[47,48]$. Interestingly, this regulatory mechanism resides not in the DTM but rather in PEX5 itself. Indeed, only intact PEX5 molecules are impeded from entering the DTM in the absence of cargo proteins; truncated PEX5 species lacking the PTS1-binding domain no longer display this property, that is, they enter the DTM in an unregulated, constitutive manner [47]. Apparently, the C-terminal half of PEX5 is a cisacting repressor of PEX5 DTM-interacting domains, which reside in its N-terminal half. 
Although structural information on the auto-regulatory mechanism of PEX5 is presently unavailable, it is possible that it relies on intramolecular interactions involving these two domains of PEX5 (see Fig. 1c). Several findings support this possibility. First, pull-down assays using recombinant proteins have shown that the two halves of PEX5 can interact with each other [49]. Second, the conformation of the N-terminal half of PEX5 is altered when PEX5 binds a PTS1 peptide as assessed by partial proteolysis experiments [50, 51]. Finally, a single missense mutation in the PTS1-binding domain of PEX5 that abolishes its PTS1-binding capacity induces conformational alterations in the N-terminal half of PEX5 and, importantly, also disrupts its auto-regulatory mechanism [50].

\section{Assembling the syringe - interaction of cargo-loaded receptors with the DTM}

The DTM (the syringe barrel) comprises 5 core components: PEX14, PEX13 and the three RING finger proteins PEX2, PEX10 and PEX12 [52, 53]. Despite an abundance of information on binary interactions between DTM components [26, 52-62], the precise organization of these proteins in the peroxisomal membrane is not known. The fact that this protein complex largely falls apart upon solubilization of the peroxisomal membrane has complicated its structural characterization [52, 53]. Nevertheless, it is clear that all of its components are transmembrane proteins, and that at least two of them, PEX14 and PEX13, have the capacity to homoligomerize and to interact directly with PEX5 [25-27, 51-65]. The PEX5-binding domains of PEX13 are exposed into the cytosol whereas the strongest PEX5-binding domain of PEX14 is either deeply embedded in the peroxisomal membrane or even exposed into the peroxisome matrix [64, 66-68]. Thus, PEX14 and PEX13 are probably the major components of the protein translocation channel (see also below).

The interaction of cargo-loaded PEX5 with the DTM occurs in two steps: docking and insertion (see Fig. 2). The first is a reversible step whereas the second is essentially irreversible in the absence of ATP [46, 69, 70]. Remarkably, DTM-inserted PEX5 displays a transmembrane topology, exposing only a small $\mathrm{N}$-terminal domain into the cytosol whereas the bulky part of its polypeptide chain faces the organelle matrix [71]. Such a topology suggests that cargoes are translocated across the peroxisomal membrane by PEX5 itself, when the receptor gets inserted into the DTM [71]. Importantly, insertion of PEX5 into the DTM does not require NTP hydrolysis in vitro and, accordingly, the 
same was recently shown to be the case for the peroxisomal import of both PTS1 and PTS2 proteins $[46,69,72]$. These findings, together with data showing that protein import into peroxisomes is a ionophore-insensitive process [72-74], strongly suggest that the driving force for protein translocation across the peroxisome membrane resides in simple protein-protein interactions involving PEX5, on one side, and components of the DTM, on the other $[46,69,72]$.

The finding that PEX5, an extremely hydrophilic protein lacking any obvious phylogenetically conserved membrane-interacting domains, acquires a transmembrane topology during the cargo protein translocation step, together with the fact that the peroxisomal membrane is impermeable to all but the smallest of the metabolites [75], also provides some information on the architecture of the DTM. Indeed, it suggests that DTM components form a flexible and gated channel in which cargo-loaded PEX5 becomes inserted to release its cargo into the peroxisome matrix. We note, however, that there are other perspectives. An interesting one can be found in the so-called transient pore model [76]. According to that model, protein translocation across the peroxisomal membrane is promoted by one or even several PEX5 molecules all of which become inserted into the peroxisomal lipid bilayer thus forming the hydrophilic channel through which cargoes are translocated [76, 77]. Two arguments seem to be at the root of that model. The first derives from the idea that most peroxisomal proteins might be imported into peroxisomes after oligomerization in the cytosol. Since some of these oligomers expose several PTSs on their surface, they might interact with several PEX5 molecules and be presented to the DTM as such [76, 77]. However, as discussed above, peroxisomal import of already oligomerized cargoes may not be that frequent. The second argument regards the fact that once at the peroxisome, PEX5 cannot be extracted from the organelle membrane by treatment with alkaline solutions, a property that might suggest that peroxisomal PEX5 is an intrinsic membrane protein (i.e., that it interacts directly with the hydrophobic phase of the membrane) [23, 78-80]. However, we have recently found that the interaction between PEX5 and PEX14, one of the most abundant components of the DTM, is remarkably stable at alkaline $\mathrm{pH}$ even in the absence of membrane lipids (Dias et al., unpublished). Thus, there is no need to assume that peroxisomal PEX5 interacts directly with the hydrophobic phase of the membrane to explain its biochemical properties. 
After insertion of cargo-loaded PEX5 or PEX5 ${ }^{\mathrm{PEX} 7}$ into the DTM, cargoes are released into the organelle matrix. Interestingly, and similarly to the insertion step, cargo-release is also a NTP-independent event and insensitive to several ionophores [69, 72]. Possibly, the receptors undergo conformational alterations during the insertion step which decrease their cargo-binding affinity, as is in fact supported by protein-protein interaction studies suggesting that some receptor-cargo interactions are decreased or even abolished by PEX14 [42, 81, 82].

\section{The receptor recycling machinery}

After cargo-release the shuttling receptors are extracted from the DTM so that they can engage in a new protein transport cycle. This is the only segment of the protein import pathway that requires energy input from ATP hydrolysis [46]. Thus, in contrast to many other protein import machineries, which use ATP/GTP hydrolysis as the driving force for the vectorial translocation of proteins across a membrane [83, 84], the PIM uses ATP not for the protein transport process itself, but rather to reset the protein transport system.

The machinery involved in receptor recycling comprises at least 10 proteins. Three of these are the DTM RING peroxins, PEX2, PEX10 and PEX12. They form a subcomplex within the DTM, as shown by biochemical and genetic studies in yeasts $[53,85]$. Also, the RING domains of all three peroxins display ubiquitin-ligase activity in in vitro assays [86-89].

Three other components of this machinery are PEX1, PEX6, and a poorly conserved tailanchored peroxin of the peroxisome membrane called PEX26 in mammals and many other organisms, APEM9 in plants and PEX15 in yeasts and some fungi [18, 90-94]. These peroxins comprise the so-called Receptor Export Module (REM), a protein complex that uses ATP hydrolysis to extract receptors from the DTM $[46,90,91]$. PEX1 and PEX6 are members of the AAA family of mechanoenzymes; they form a heterohexameric ring, best described as a trimer of PEX1/PEX6 heterodimers, which is anchored to the peroxisome membrane by PEX26/APEM9/PEX15 [92-98]. Finally, the export machinery also comprises ubiquitin, an ubiquitin-activating enzyme, an ubiquitinconjugating enzyme (E2D1/2/3, in mammals; the PEX4-PEX22 complex in yeasts, fungi and plants), and AWP1, a proposed ubiquitin-binding adaptor of the mammalian PEX1/PEX6 complex [99-101]. 


\section{Disassembling the syringe - recycling of receptors}

Extraction of PEX5 or PEX5 ${ }^{\mathrm{PEX} 7}$ from the DTM involves two distinct steps, namely, monoubiquitination of PEX5 and ATP-dependent dislocation of monoubiquitinated PEX5 (Ub-PEX5) back into the cytosol. PEX7 is not ubiquitinated during this event but its export requires monoubiquitination and dislocation of PEX5 from the DTM. Interestingly, Ub-PEX5 and PEX7 seem to leave the DTM separately, with the former displaying faster export kinetics than the latter. Apparently, extraction of Ub-PEX5 from the DTM also disrupts its interaction with PEX7. How exactly PEX7 is subsequently released into the cytosol is still unknown but it might simply involve the spontaneous disruption of a weak protein-protein interaction with the DTM [48, 102]. Monoubiquitination of PEX5 displays some noteworthy properties. First, in contrast to classical ubiquitination which targets lysine residues, the final acceptor of ubiquitin is a phylogenetically conserved cysteine residue present in the small cytosol-exposed domain of DTM-embedded PEX5 [100, 103] (see Fig. 1b). The reason for this is still not fully comprehended but, as discussed elsewhere [104], this type of unconventional ubiquitination may, on one hand, allow a redox regulation of the PEX5-mediated protein import pathway and, on the other, reduce the probability that dislocated (i.e., cytosolic) Ub-PEX5 ends up in the ubiquitin-proteasome pathway. Data supporting both possibilities have been provided recently $[105,106]$. Second, monoubiquitination of PEX5 at the DTM is an integral and mandatory step of the PEX5 peroxisome-cytosol cycle, and not the result of some regulatory event occurring at the PIM [103, 104, 107, 108]. Finally, monoubiquitination of PEX5 is completely dependent on the three RING peroxins and occurs only after cargo-dependent insertion of the receptor into the DTM $[48,69$, 109]. The actual monoubiquitination mechanism remains largely uncharacterized. It is known that E2D1/2/3 in mammals and the PEX4-PEX22 complex in yeasts are the ubiquitin conjugating enzymes involved in this step $[99,100]$ but which of the RING peroxin(s), if any alone, participate in this reaction remains undefined [110]. After monoubiquitination, PEX5 is dislocated by the REM. Recognition of Ub-PEX5 by the REM probably involves a direct interaction between the ubiquitin moiety and the REM because modification of cys11 of DTM-embedded PEX5 with a bulky ubiquitin analog results in a PEX5 protein that is no longer an export substrate [103]. Thus, it is not 
monoubiquitination of PEX5 per se but rather the protein interface provided by an intact ubiquitin bound to PEX5 that triggers the REM. However, it is unlikely that the UbPEX5.REM interaction is limited to this single-site contact. Indeed, some recent data suggest that PEX5 itself and PEX14 may also interact directly with the REM [90, 111].

Extraction of DTM-embedded Ub-PEX5 into the cytosol is very fast in vitro (half-life < 2 $\min )[48,70]$. This step is absolutely dependent on ATP hydrolysis but the stoichiometry of the reaction, i.e., the number of ATPs hydrolyzed per Ub-PEX5 dislocated, is unknown. The same is true for the mechanism used by PEX1/PEX6 to extract Ub-PEX5 from the DTM. Although the structure of the yeast complex was recently determined, the data did not unveil its mechanism, as discussed recently [98]. Nevertheless, by analogy with other members of the AAA family it was proposed that Ub-PEX5 is moved "into, and perhaps even through," the central pore of the PEX1/PEX6 ring [98]. A recent finding might favor the second possibility, i.e., that at least a portion of PEX5 polypeptide chain is threaded through the REM pore during the extraction step. Indeed, it has been shown that a PEX5 protein harboring a bulky EGFP moiety at its C-terminus can still enter the DTM, where it is monoubiquitinated and recognized by the REM. However, its export is severely compromised resulting in the accumulation of a partially dislocated species having most of the PEX5 moiety already exposed into the cytosol while the EGFP portion plus a few PEX5 C-terminal residues is still associated with the organelle, presumably trapped at the REM [112].

\section{Closing the cycle - PEX5 deubiquitination}

Dislocation of Ub-PEX5 into the cytosol is followed by its rapid deubiquitination, the last step of the PEX5-mediated protein import pathway. The most active deubiquitinating enzyme (DUB) involved in this event has been identified in both yeast and mammals. These are UBP15 and USP9X, respectively [107, 113]. However, it is clear that these enzymes do not provide the only way to deubiquitinate PEX5 because deletion or knockdown of the corresponding genes does not lead to the accumulation of cytosolic UbPEX5. Possibly, other DUBs also contribute to this reaction. It is also feasible that a fraction of Ub-PEX5 is deubiquitinated in a non-enzymatic manner since the labile thioester bond linking ubiquitin to PEX5 becomes highly sensitive to nucleophilic attack (e.g., by glutathione (GSH)) after extraction of Ub-PEX5 from the DTM [104]. 


\section{Conclusions and outlook}

Our knowledge on the PEX5-mediated protein import pathway has increased remarkably in recent years. Yet, it is evident that there are still large gaps in our understanding of the PIM. A particularly large one regards the composition and architecture of the hydrophilic channel through which matrix proteins are translocated into the peroxisome matrix. Clearly, we need the power of structural biology to get at least some snapshots of how all the proteins that comprise the DTM are organized. Another line of research that will surely provide valuable information regards the functional/structural characterization of the PIM in more divergent/ancient organisms. For instance, some PEX14 proteins (e.g., GeneBank acc. number: EJK45126.1, [114]) possess a PUB domain, which is known to mediate interactions with p97 [115], a protein that similarly to PEX1/6 is a member of the AAA family of mechanoenzymes. If true, this might suggest that at a certain time in evolution p97 was the mechanoenzyme in charge of dislocating receptors from the DTM. Clearly, we will see many exciting discoveries on the peroxisomal matrix protein import machinery in the coming years.

\section{Competing financial interests}

The authors declare that they have no competing financial interests.

\section{Acknowledgments}

We would like to thank Dr. Marc Fransen (KU Leuven) for his critical reading of the manuscript. This work was financed by FEDER - Fundo Europeu de Desenvolvimento Regional, funds through the COMPETE 2020 - Operacional Programme for Competitiveness and Internationalization (POCI), Portugal 2020, and by Portuguese funds through FCT - Fundação para a Ciência e a Tecnologia/ Ministério da Ciência, Tecnologia e Inovação in the framework of the projects "Institute for Research and Innovation in Health Sciences" (POCI-01-0145-FEDER-007274) and "The molecular mechanisms of peroxisome biogenesis" (PTDC/BEX-BCM/2311/2014), and through Norte 2020 - Programa Operacional Regional do Norte, under the application of the "Porto Neurosciences and Neurologic Disease Research Initiative at i3S (NORTE-010145-FEDER-000008)”. T.F., T.A.R., A.F.D., A.B.B. and D.B. were supported by 
Fundação para a Ciência e a Tecnologia, Programa Operacional Potencial Humano do QREN and Fundo Social Europeu.

\section{References}

1. Islinger M, Cardoso MJR, Schrader M. 2010. Be different--the diversity of peroxisomes in the animal kingdom. Biochim. Biophys. Acta 1803: 881-97.

2. Islinger M, Grille S, Fahimi HD, Schrader M. 2012. The peroxisome: an update on mysteries. Histochem. Cell Biol. 137: 547-74.

3. Kikuchi M, Hatano N, Yokota S, Shimozawa N, et al. 2004. Proteomic analysis of rat liver peroxisome: presence of peroxisome-specific isozyme of Lon protease. J. Biol. Chem. 279: 421-8.

4. Wiese S, Gronemeyer T, Ofman R, Kunze M, et al. 2007. Proteomics characterization of mouse kidney peroxisomes by tandem mass spectrometry and protein correlation profiling. Mol. Cell. Proteomics 6: 2045-57.

5. Waterham HR, Ferdinandusse S, Wanders RJA. 2016. Human disorders of peroxisome metabolism and biogenesis. Biochim. Biophys. Acta 1863: 922-33.

6. De Munter S, Verheijden S, Régal L, Baes M. 2015. Peroxisomal Disorders: A Review on Cerebellar Pathologies. Brain Pathol. 25: 663-78.

7. Berger J, Gärtner J. 2006. X-linked adrenoleukodystrophy: clinical, biochemical and pathogenetic aspects. Biochim. Biophys. Acta 1763: 1721-32.

8. Berger J, Dorninger F, Forss-Petter S, Kunze M. 2016. Peroxisomes in brain development and function. Biochim. Biophys. Acta 1863: 934-55.

9. Schrader M, Costello JL, Godinho LF, Azadi AS, et al. 2016. Proliferation and fission of peroxisomes - An update. Biochim. Biophys. Acta 1863: 971-83.

10. Fujiki Y, Matsuzono Y, Matsuzaki T, Fransen M. 2006. Import of peroxisomal membrane proteins: the interplay of Pex3p- and Pex 19p-mediated interactions. Biochim. Biophys. Acta 1763: 1639-46.

11. Hua R, Kim PK. 2016. Multiple paths to peroxisomes: Mechanism of peroxisome maintenance in mammals. Biochim. Biophys. Acta 1863: 881-91.

12. Cross LL, Ebeed HT, Baker A. 2016. Peroxisome biogenesis, protein targeting mechanisms and PEX gene functions in plants. Biochim. Biophys. Acta-Mol. Cell Res. 1863: 850-62. 
13. Lazarow PB, Fujiki Y. 1985. Biogenesis of peroxisomes. Annu. Rev. Cell Biol. 1: 489-530.

14. Lazarow PB. 2006. The import receptor Pex7p and the PTS2 targeting sequence. Biochim. Biophys. Acta 1763: 1599-604.

15. Dodt G, Gould SJ. 1996. Multiple PEX genes are required for proper subcellular distribution and stability of Pex5p, the PTS1 receptor: evidence that PTS1 protein import is mediated by a cycling receptor. J. Cell Biol. 135: 1763-74.

16. Marzioch M, Erdmann R, Veenhuis M, Kunau WH. 1994. PAS7 encodes a novel yeast member of the WD-40 protein family essential for import of 3oxoacyl-CoA thiolase, a PTS2-containing protein, into peroxisomes. EMBO J. 13: 4908-18.

17. Brocard C, Hartig A. 2006. Peroxisome targeting signal 1: is it really a simple tripeptide? Biochim. Biophys. Acta 1763: 1565-73.

18. Kiel JAKW, Veenhuis M, van der Klei IJ. 2006. PEX Genes in Fungal Genomes: Common, Rare or Redundant. Traffic 7: 1291-303.

19. Dodt G, Warren D, Becker E, Rehling P, et al. 2001. Domain mapping of human PEX5 reveals functional and structural similarities to Saccharomyces cerevisiae Pex18p and Pex21p. J. Biol. Chem. 276: 41769-81.

20. Einwächter H, Sowinski S, Kunau W, Schliebs W. 2001. Yarrowia lipolytica Pex20p, Saccharomyces cerevisiae Pex18p/Pex21p and mammalian Pex5pL fulfil a common function in the early steps of the peroxisomal PTS2 import pathway. EMBO Rep. 2: 1035-9.

21. Gatto G, Geisbrecht B, Gould SJ, Berg JM. 2000. Peroxisomal targeting signal1 recognition by the TPR domains of human PEX5. Nat. Struct. Biol. 7: 1091-5.

22. Dodt G, Braverman N, Wong C, Moser A, et al. 1995. Mutations in the PTS1 receptor gene, PXR1, define complementation group 2 of the peroxisome biogenesis disorders. Nat. Genet. 9: 115-25.

23. Terlecky SR, Nuttley WM, McCollum D, Sock E, et al. 1995. The Pichia pastoris peroxisomal protein PAS8p is the receptor for the C-terminal tripeptide peroxisomal targeting signal. EMBO J. 14: 3627-34.

24. Carvalho AF, Costa-Rodrigues J, Correia I, Costa Pessoa J, et al. 2006. The Nterminal half of the peroxisomal cycling receptor Pex5p is a natively unfolded 
domain. J. Mol. Biol. 356: 864-75.

25. Bottger G, Barnett P, Klein AT, Kragt A, et al. 2000. Saccharomyces cerevisiae PTS1 receptor Pex 5p interacts with the SH3 domain of the peroxisomal membrane protein Pex13p in an unconventional, non-PXXP-related manner. Mol. Biol. Cell 11: 3963-76.

26. Otera H, Setoguchi K, Hamasaki M, Kumashiro T, et al. 2002. Peroxisomal targeting signal receptor Pex $5 \mathrm{p}$ interacts with cargoes and import machinery components in a spatiotemporally differentiated manner: conserved Pex $5 \mathrm{p}$ WXXXF/Y motifs are critical for matrix protein import. Mol. Cell. Biol. 22: 163955.

27. Neuhaus A, Kooshapur H, Wolf J, Meyer NH, et al. 2014. A novel Pex14 protein-interacting site of human Pex 5 is critical for matrix protein import into peroxisomes. J. Biol. Chem. 289: 437-48.

28. Ghys K, Fransen M, Mannaerts GP, Van Veldhoven PP. 2002. Functional studies on human Pex7p: subcellular localization and interaction with proteins containing a peroxisome-targeting signal type 2 and other peroxins. Biochem. J. 365: 41-50.

29. Pan D, Nakatsu T, Kato H. 2013. Crystal structure of peroxisomal targeting signal-2 bound to its receptor complex Pex7p-Pex21p. Nat. Struct. Mol. Biol. 20: 987-93.

30. Zhang JW, Lazarow PB. 1996. Peb1p (Pas7p) is an intraperoxisomal receptor for the NH2-terminal, type 2, peroxisomal targeting sequence of thiolase: Peb1p itself is targeted to peroxisomes by an NH2-terminal peptide. J. Cell Biol. 132: 325-34.

31. Elgersma Y, Elgersma-hooisma M, Wenzel T, Mccaffery JM, et al. 1998. A Mobile PTS2 Receptor for Peroxisomal Protein Import in Pichia pastoris. J. Cell Biol. 140: 807-20.

32. Rehling P, Marzioch M, Niesen F, Wittke E, et al. 1996. The import receptor for the peroxisomal targeting signal 2 (PTS2) in Saccharomyces cerevisiae is encoded by the PAS7 gene. EMBO J. 15: 2901-13.

33. Braverman N, Dodt G, Gould SJ, Valle D. 1998. An isoform of pex5p, the human PTS1 receptor, is required for the import of PTS2 proteins into peroxisomes. Hum. Mol. Genet. 7: 1195-205. 
34. Otera H, Okumoto K, Tateishi K, Ikoma Y, et al. 1998. Peroxisome targeting signal type 1 (PTS1) receptor is involved in import of both PTS1 and PTS2: studies with PEX5-defective CHO cell mutants. Mol. Cell. Biol. 18: 388-99.

35. Léon S, Goodman JM, Subramani S. 2006. Uniqueness of the mechanism of protein import into the peroxisome matrix: transport of folded, co-factor-bound and oligomeric proteins by shuttling receptors. Biochim. Biophys. Acta 1763: $1552-64$.

36. Gunkel K, Veenhuis M, van der Klei IJ. 2005. Protein translocation machineries: how organelles bring in matrix proteins. FEMS Yeast Res. 5: 103745.

37. Glover JR, Andrews DW, Rachubinski RA. 1994. Saccharomyces cerevisiae peroxisomal thiolase is imported as a dimer. Proc. Natl. Acad. Sci. USA 91: 10541-5.

38. McNew JA, Goodman JM. 1994. An oligomeric protein is imported into peroxisomes in vivo. J. Cell Biol. 127: 1245-57.

39. Lee MS, Mullen RT, Trelease RN. 1997. Oilseed isocitrate lyases lacking their essential type 1 peroxisomal targeting signal are piggybacked to glyoxysomes. Plant Cell 9: 185-97.

40. Dias AF, Francisco T, Rodrigues TA, Grou CP, et al. 2016. The first minutes in the life of a peroxisomal matrix protein. Biochim. Biophys. Acta 1863: 814-20.

41. Freitas MO, Francisco T, Rodrigues TA, Lismont C, et al. 2015. The peroxisomal protein import machinery displays a preference for monomeric substrates. Open Biol. 5: 140236.

42. Freitas MO, Francisco T, Rodrigues TA, Alencastre IS, et al. 2011. PEX5 protein binds monomeric catalase blocking its tetramerization and releases it upon binding the N-terminal domain of PEX14. J. Biol. Chem. 286: 40509-19.

43. Klein ATJ, van den Berg M, Bottger G, Tabak HF, et al. 2002. Saccharomyces cerevisiae acyl-CoA oxidase follows a novel, non-PTS1, import pathway into peroxisomes that is dependent on Pex5p. J. Biol. Chem. 277: 25011-9.

44. Gunkel K, Dijk R Van, Veenhuis M, Klei IJ Van Der, et al. 2004. Routing of Hansenula polymorpha Alcohol Oxidase : An Alternative Peroxisomal Proteinsorting Machinery. Mol. Biol. Cell 15: 1347-55. 
45. Uversky VN. 2013. The UBE2E proteins as conjugating dispersers: Extending function with extended extensions. J. Mol. Biol. 425: 4067-70.

46. Oliveira ME, Gouveia AM, Pinto RA, Sá-Miranda C, et al. 2003. The energetics of Pex5p-mediated peroxisomal protein import. J. Biol. Chem. 278: 39483-8.

47. Gouveia AM, Guimarães CP, Oliveira ME, Sá-Miranda C, et al. 2003. Insertion of Pex5p into the peroxisomal membrane is cargo protein-dependent. $J$. Biol. Chem. 278: 4389-92.

48. Rodrigues TA, Alencastre IS, Francisco T, Brites P, et al. 2014. A PEX7centered perspective on the peroxisomal targeting signal type 2-mediated protein import pathway. Mol. Cell. Biol. 34: 2917-28.

49. Harano T, Nose S, Uezu R, Shimizu N, et al. 2001. Hsp70 regulates the interaction between the peroxisome targeting signal type 1 (PTS1)-receptor Pex5p and PTS1. Biochem. J. 357: 157-65.

50. Carvalho AF, Grou CP, Pinto MP, Alencastre IS, et al. 2007. Functional characterization of two missense mutations in Pex5p - C11S and N526K. Biochim. Biophys. Acta 1773: 1141-8.

51. Costa-Rodrigues J, Carvalho AF, Fransen M, Hambruch E, et al. 2005. Pex5p, the peroxisomal cycling receptor, is a monomeric non-globular protein. J. Biol. Chem. 280: 24404-11.

52. Reguenga C, Oliveira ME, Gouveia AM, Sá-Miranda C, et al. 2001. Characterization of the mammalian peroxisomal import machinery: Pex $2 p$, Pex 5p, Pex12p, and Pex14p are subunits of the same protein assembly. J. Biol. Chem. 276: $29935-42$.

53. Agne B, Meindl NM, Niederhoff K, Einwächter H, et al. 2003. Pex8p: an intraperoxisomal organizer of the peroxisomal import machinery. Mol. Cell 11: 635-46.

54. Fransen M, Brees C, Ghys K, Amery L, et al. 2002. Analysis of Mammalian Peroxin Interactions Using a Non-transcription-based Bacterial Two-hybrid Assay. Mol. Cell. Proteomics 1: 243-52.

55. Schell-steven A, Stein K, Amoros M, Landgraf C, et al. 2005. Identification of a Novel, Intraperoxisomal Pex14-Binding Site in Pex13 : Association of Pex13 with 
the Docking Complex Is Essential for Peroxisomal Matrix Protein Import. Mol. Cell. Biol. 25: 3007-18.

56. Pires JR, Hong X, Brockmann C, Volkmer-Engert R, et al. 2003. The ScPex13p SH3 Domain Exposes Two Distinct Binding Sites for Pex5p and Pex14p. J. Mol. Biol. 326: 1427-35.

57. Harano T, Shimizu N, Otera H, Fujiki Y. 1999. Transmembrane topology of the peroxin, Pex2p, an essential component for the peroxisome assembly. J. Biochem. 125: $1168-74$.

58. Itoh R, Fujiki Y. 2006. Functional domains and dynamic assembly of the peroxin Pex14p, the entry site of matrix proteins. J. Biol. Chem. 281: 10196-205.

59. Krause C, Rosewich H, Woehler A, Gärtner J. 2013. Functional analysis of PEX13 mutation in a Zellweger syndrome spectrum patient reveals novel homooligomerization of PEX13 and its role in human peroxisome biogenesis. Hum. Mol. Genet. : 1-14.

60. Barnett P, Bottger G, Klein AT, Tabak HF, et al. 2000. The peroxisomal membrane protein Pex13p shows a novel mode of SH3 interaction. EMBO J. 19: 6382-91.

61. Fransen M, Terlecky SR, Subramani S. 1998. Identification of a human PTS1 receptor docking protein directly required for peroxisomal protein import. Proc. Natl. Acad. Sci. U. S. A. 95: 8087-92.

62. Shimizu N, Itoh R, Hirono Y, Otera H, et al. 1999. The Peroxin Pex14p - cDNA Cloning by functional complementation on a Chinese Hamster Ovary Cell mutant, characterization, and functional analysis. J. Biol. Chem. 274: 12593-604.

63. Okumoto K, Fujiki Y. 1997. PEX12 encodes an integral membrane protein of peroxisomes. Nat. Genet. 17: 265-6.

64. Oliveira MEM, Reguenga C, Gouveia AMM, Guimarães CP, et al. 2002. Mammalian Pex14p: membrane topology and characterisation of the Pex14pPex14p interaction. Biochim. Biophys. Acta 1567: 13-22.

65. Williams C, van den Berg M, Distel B. 2005. Saccharomyces cerevisiae Pex 14p contains two independent Pex5p binding sites, which are both essential for PTS1 protein import. FEBS Lett. 579: 3416-20.

66. Toyama R, Mukai S, Itagaki A, Tamura S, et al. 1999. Isolation, 
characterization and mutation analysis of PEX13-defective Chinese hamster ovary cell mutants. Hum. Mol. Genet. 8: 1673-81.

67. Gould SJ, Kalish JE, Morrell JC, Bjorkman J, et al. 1996. Pex13p is an SH3 protein of the peroxisome membrane and a docking factor for the predominantly cytoplasmic PTS1 receptor. J. Cell Biol. 135: 85-95.

68. Will GK, Soukupova M, Hong X, Erdmann KS, et al. 1999. Identification and characterization of the human orthologue of yeast Pex14p. Mol. Cell. Biol. 19: 2265-77.

69. Francisco T, Rodrigues TA, Freitas MO, Grou CP, et al. 2013. A cargocentered perspective on the PEX5-mediated peroxisomal protein import pathway. J. Biol. Chem. 288: 29151-9.

70. Costa-Rodrigues J, Carvalho AF, Gouveia AM, Fransen M, et al. 2004. The N terminus of the peroxisomal cycling receptor, Pex $5 p$, is required for redirecting the peroxisome-associated peroxin back to the cytosol. J. Biol. Chem. 279: 46573-9.

71. Gouveia AM, Guimarães CP, Oliveira ME, Reguenga C, et al. 2003. Characterization of the peroxisomal cycling receptor, Pex $5 \mathrm{p}$, using a cell-free in vitro import system. J. Biol. Chem. 278: 226-32.

72. Alencastre IS, Rodrigues TA, Grou CP, Fransen M, et al. 2009. Mapping the cargo protein membrane translocation step into the PEX5 cycling pathway. J. Biol. Chem. 284: 27243-51.

73. Wendland M, Subramani S. 1993. Cytosol-dependent peroxisomal protein import in a permeabilized cell system. J. Cell Biol. 120: 675-85.

74. Imanaka T, Small GM, Lazarow PB. 1987. Translocation of acyl-CoA oxidase into peroxisomes requires ATP hydrolysis but not a membrane potential. J. Cell Biol. 105: 2915-22.

75. Antonenkov VD, Hiltunen JK. 2012. Transfer of metabolites across the peroxisomal membrane. Biochim. Biophys. Acta 1822: 1374-86.

76. Erdmann R, Schliebs W. 2005. Peroxisomal matrix protein import: the transient pore model. Nat. Rev. Mol. Cell Biol. 6: 738-42.

77. Meinecke M, Bartsch P, Wagner R. 2016. Peroxisomal protein import pores. Biochim. Biophys. Acta 1863: 821-7.

78. Fransen M, Brees C, Baumgart E, Vanhooren JCT, et al. 1995. Identification 
and characterization of the putative human peroxisomal c-terminal targeting signal import receptor. J. Biol. Chem. 270: 7731-6.

79. Wiemer EA, Nuttley WM, Bertolaet BL, Li X, et al. 1995. Human peroxisomal targeting signal-1 receptor restores peroxisomal protein import in cells from patients with fatal peroxisomal disorders. J. Cell Biol. 130: 51-65.

80. Gouveia AM, Reguenga C, Oliveira ME, Sa-Miranda C, et al. 2000.

Characterization of peroxisomal Pex $5 p$ from rat liver. Pex $5 p$ in the Pex5p-Pex $14 p$ membrane complex is a transmembrane protein. J. Biol. Chem. 275: 32444-51.

81. Lanyon-Hogg T, Hooper J, Gunn S, Warriner SL, et al. 2014. PEX14 binding to Arabidopsis PEX5 has differential effects on PTS1 and PTS2 cargo occupancy of the receptor. FEBS Lett. 588: 2223-9.

82. Madrid KP, Crescenzo G De, Wang S, Jardim A. 2004. Modulation of the Leishmania donovani peroxin 5 quaternary structure by peroxisomal targeting signal 1 ligands. Mol. Cell. Biol. 24: 7331-44.

83. Schulz C, Schendzielorz A, Rehling P. 2015. Unlocking the presequence import pathway. Trends Cell Biol. 25: 265-75.

84. Bölter B, Soll J. 2016. Once upon a Time - Chloroplast Protein Import Research from Infancy to Future Challenges. Mol. Plant 9: 798-812.

85. El Magraoui F, Bäumer BE, Platta HW, Baumann JS, et al. 2012. The RINGtype ubiquitin ligases Pex2p, Pex10p and Pex 12p form a heteromeric complex that displays enhanced activity in an ubiquitin conjugating enzyme-selective manner. FEBS J. 279: 2060-70.

86. Williams C, van den Berg M, Geers E, Distel B. 2008. Pex10p functions as an E3 ligase for the Ubc4p-dependent ubiquitination of Pex5p. Biochem. Biophys. Res. Commun. 374: 620-4.

87. Platta HW, El Magraoui F, Bäumer BE, Schlee D, et al. 2009. Pex2 and pex12 function as protein-ubiquitin ligases in peroxisomal protein import. Mol. Cell. Biol. 29: $5505-16$.

88. Kaur N, Zhao Q, Xie Q, Hu J. 2013. Arabidopsis RING peroxins are E3 ubiquitin ligases that interact with two homologous ubiquitin receptor proteins. $J$. Integr. Plant Biol. 55: 108-20.

89. Platta HW, Brinkmeier R, Reidick C, Galiani S, et al. 2016. Regulation of 
peroxisomal matrix protein import by ubiquitination. Biochim. Biophys. Acta Mol. Cell Res. 1863: 838-49.

90. Miyata N, Fujiki Y. 2005. Shuttling Mechanism of Peroxisome Targeting Signal Type 1 Receptor Pex 5 : ATP-Independent Import and ATP-Dependent Export. Mol. Cell. Biol. 25: 10822-32.

91. Platta HW, Grunau S, Rosenkranz K, Girzalsky W, et al. 2005. Functional role of the AAA peroxins in dislocation of the cycling PTS1 receptor back to the cytosol. Nat. Cell Biol. 7: 817-22.

92. Matsumoto N, Tamura S, Fujiki Y. 2003. The pathogenic peroxin Pex26p recruits the Pex1p-Pex6p AAA ATPase complexes to peroxisomes. Nat. Cell Biol. 5: 454-60.

93. Goto S, Mano S, Nakamori C, Nishimura M. 2011. Arabidopsis ABERRANT PEROXISOME MORPHOLOGY9 is a peroxin that recruits the PEX1-PEX6 complex to peroxisomes. Plant Cell 23: 1573-87.

94. Birschmann I, Stroobants AK, Berg M Van Den, Schafer A, et al. 2003. Pex15p of Saccharomyces cerevisiae Provides a Molecular Basis for Recruitment of the AAA Peroxin Pex6p to Peroxisomal Membranes. Mol. Biol. Cell 14: 222636.

95. Blok NB, Tan D, Wang RY-R, Penczek PA, et al. 2015. Unique double-ring structure of the peroxisomal Pex1/Pex6 ATPase complex revealed by cryoelectron microscopy. Proc. Natl. Acad. Sci. U. S. A. 112: 201500257.

96. Ciniawsky S, Grimm I, Saffian D, Girzalsky W, et al. 2015. Molecular snapshots of the Pex1/6 AAA+ complex in action. Nat. Commun. 6: 7331.

97. Gardner BM, Chowdhury S, Lander GC, Martin A. 2015. The Pex1/Pex6 complex is a heterohexameric AAA+ motor with alternating and highly coordinated subunits. J. Mol. Biol. 427: 1375-88.

98. Tan D, Blok NB, Rapoport TA, Walz T. 2016. Structures of the double-ring AAA ATPase Pex1-Pex6 involved in peroxisome biogenesis. FEBS J. 283: 98692.

99. Grou CP, Carvalho AF, Pinto MP, Wiese S, et al. 2008. Members of the E2D (UbcH5) family mediate the ubiquitination of the conserved cysteine of Pex5p, the peroxisomal import receptor. J. Biol. Chem. 283: 14190-7. 
100. Williams C, van den Berg M, Sprenger RR, Distel B. 2007. A conserved cysteine is essential for Pex4p-dependent ubiquitination of the peroxisomal import receptor Pex5p. J. Biol. Chem. 282: 22534-43.

101. Miyata N, Okumoto K, Mukai S, Noguchi M, et al. 2012. AWP1/ZFAND6 functions in Pex5 export by interacting with cys-monoubiquitinated Pex5 and Pex6 AAA ATPase. Traffic 13: 168-83.

102. Rodrigues TA, Grou CP, Azevedo JE. 2015. Revisiting the intraperoxisomal pathway of mammalian PEX7. Sci. Rep. 5: 11806.

103. Carvalho AF, Pinto MP, Grou CP, Alencastre IS, et al. 2007. Ubiquitination of mammalian Pex5p, the peroxisomal import receptor. J. Biol. Chem. 282: 3126772.

104. Grou CP, Carvalho AF, Pinto MP, Huybrechts SJ, et al. 2009. Properties of the ubiquitin-pex5p thiol ester conjugate. J. Biol. Chem. 284: 10504-13.

105. Apanasets O, Grou CP, Van Veldhoven PP, Brees C, et al. 2014. PEX5, the shuttling import receptor for peroxisomal matrix proteins, is a redox-sensitive protein. Traffic 15: 94-103.

106. Schwartzkopff B, Platta HW, Hasan S, Girzalsky W, et al. 2015. Cysteinespecific ubiquitination protects the peroxisomal import receptor Pex 5 p against proteasomal degradation. Biosci. Rep. 35: e00215.

107. Grou CP, Francisco T, Rodrigues TA, Freitas MO, et al. 2012. Identification of ubiquitin-specific protease 9X (USP9X) as a deubiquitinase acting on the ubiquitin-peroxin 5 (PEX5) thioester conjugate. J. Biol. Chem. 287: 12815-27.

108. Léon S, Subramani S. 2007. A conserved cysteine residue of Pichia pastoris Pex20p is essential for its recycling from the peroxisome to the cytosol. J. Biol. Chem. 282: 7424-30.

109. Liu X, Subramani S. 2013. Unique Requirements for Mono- and Polyubiquitination of the Peroxisomal Targeting Signal Co-receptor, Pex20. J. Biol. Chem. 288: 7230-40.

110. Francisco T, Rodrigues TA, Pinto MP, Carvalho AF, et al. 2014. Ubiquitin in the peroxisomal protein import pathway. Biochimie 98: 29-35.

111. Tamura S, Matsumoto N, Takeba R, Fujiki Y. 2014. AAA peroxins and their recruiter Pex26p modulate the interactions of peroxins involved in peroxisomal 
protein import. J. Biol. Chem. 289: 24336-46.

112. Nordgren M, Francisco T, Lismont C, Hennebel L, et al. 2015. Export-deficient monoubiquitinated PEX5 triggers peroxisome removal in SV40 large T antigentransformed mouse embryonic fibroblasts. Autophagy 11: 1326-40.

113. Debelyy MO, Platta HW, Saffian D, Hensel A, et al. 2011. Ubp15p, a ubiquitin hydrolase associated with the peroxisomal export machinery. J. Biol. Chem. 286: $28223-34$.

114. Lommer M, Specht M, Roy A-S, Kraemer L, et al. 2012. Genome and low-iron response of an oceanic diatom adapted to chronic iron limitation. Genome Biol. 13: R66.

115. Madsen L, Seeger M, Semple CA, Hartmann-Petersen R. 2009. New ATPase regulators--p97 goes to the PUB. Int. J. Biochem. Cell Biol. 41: 2380-8.

116. Grunau S, Schliebs W, Linnepe R, Neufeld C, et al. 2009. Peroxisomal targeting of PTS2 pre-import complexes in the yeast Saccharomyces cerevisiae. Traffic 10: 451-60.

117. Kunze M, Malkani N, Maurer-Stroh S, Wiesinger C, et al. 2015. Mechanistic insights into PTS2-mediated peroxisomal protein import: the co-receptor PEX5L drastically increases the interaction strength between the cargo protein and the receptor PEX7. J. Biol. Chem. 290: 4928-40.

118. Knott TG, Birdsey GM, Sinclair KE, Gallagher IM, et al. 2000. The peroxisomal targeting sequence type 1 receptor, Pex $5 \mathrm{p}$, and the peroxisomal import efficiency of alanine:glyoxylate aminotransferase. Biochem. J. 352 Pt 2: 409-18. 


\section{Figures legend}

Figure 1. A: The peroxisomal targeting signals. The PTS1 is a small peptide present at the extreme C-termini of many peroxisomal matrix proteins. It frequently ends with the sequence SKL [17]. These proteins are recognized by the shuttling receptor PEX5 [17]. The PTS2 is a degenerated nonapeptide found at the N-termini of a few proteins [14]. In mammals, plants and many other organisms, PTS2 proteins are transported to the peroxisome by a PEX5 ${ }^{\mathrm{PEX} 7}$ protein complex [14], whereas in yeasts and fungi this is done by a complex comprising PEX7 and a PEX5-like peroxin $[14,18,19]$. It is possible that newly synthesized PTS2 proteins interact first with cytosolic PEX7, and that PEX5 (or PEX5-like peroxins) joins the complex subsequently $[116,117] . \quad \mathbf{B}$ : Functional/structural domains of PEX5. The N-terminal half of PEX5 is an intrinsically disordered region. It contains eight pentapeptide motifs (shown in dark gray) all of which have been shown to interact with PEX14 [26, 27]. Some of these motifs also interact with PEX13 [26]. The conserved cysteine residue (cysteine 11 in human PEX5), and a PEX7/PTS2-binding region (shown in blue; [19, 20, 29, 102, 117] are also indicated. The structure of the C-terminal half of human PEX5 is known [21] (PDB ID: 1FCH). The TPRs (shown in magenta) form the PTS1-binding domain of PEX5. C: The auto-regulatory mechanism of PEX5. The hypothetical model shown is based on the finding that the C-terminal half of PEX5 is a cis-acting repressor of the DTM-interacting domain of PEX5. Free PEX5 oscillates between two conformations, one inactive and the other active, the latter being much less populated than the former; cargoes interact with the active form of PEX5, maintaining the DTM-interacting region of PEX5 in an active state. Transition between inactive and active PEX5 might also be triggered by binding of the cargo protein to PEX5; however, this possibility would not explain why overexpression of PEX5 in cells leads to a partial inhibition of peroxisomal import [118].

Figure 2. The peroxisomal matrix protein import mechanism. Peroxisomal matrix proteins $(\mathrm{CP})$ are synthesized on cytosolic ribosomes and bound by the shuttling receptor PEX5 (stage 1a). The PEX5-cargo complex then docks at (stage 1b) and becomes inserted into the DTM (stage 2) resulting in cargo translocation across the peroxisomal membrane and its release into the organelle matrix. PEX5 is then monoubiquitinated at a conserved cysteine residue (cysteine 11 in mammals) (stage 3a), a mandatory 
modification for the subsequent interaction with the receptor export module (REM; stage 3b). Finally, after the ATP-dependent extraction of monoubiquitinated PEX5 into the cytosol (stage 4), PEX5 is deubiquitinated probably by a combination of non-enzymatic (e.g., glutathione (GSH)) and enzymatic mechanisms (e.g., USP9X in mammals). Free PEX5 (stage 0) can then start a new protein transport cycle. Import of PTS2-containing proteins involves the receptor PEX5 ${ }^{\mathrm{PEX} 7}$. PEX7 remains bound to PEX5 during most of the steps of this pathway (see also $[48,102]$ ). For simplicity PEX7 is not shown in the figure. E1, ubiquitin-activating enzyme, E2, ubiquitin-conjugating enzyme (i.e., E2D1/2/3), E3, ubiquitin RING ligases (i.e., PEX2, PEX10 and PEX12), PPi, pyrophosphate, $\mathrm{Ub}$, ubiquitin. 
A)

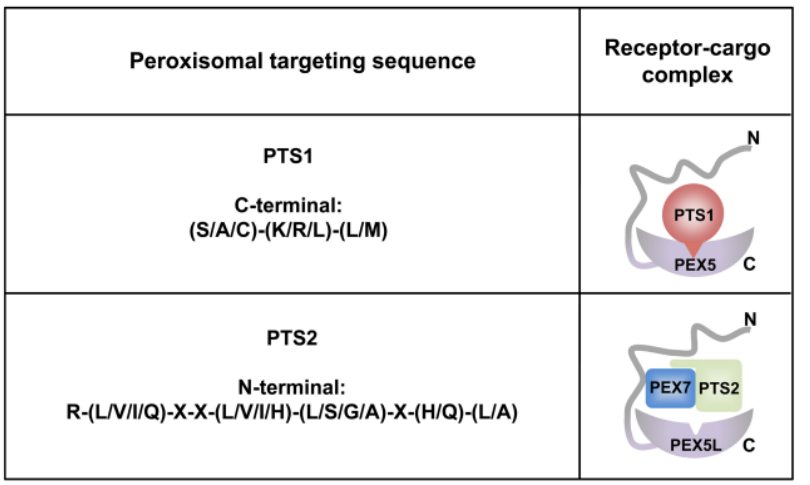

B)

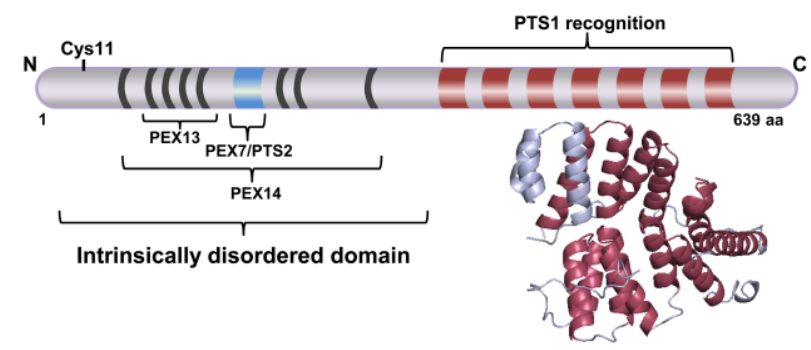

C)

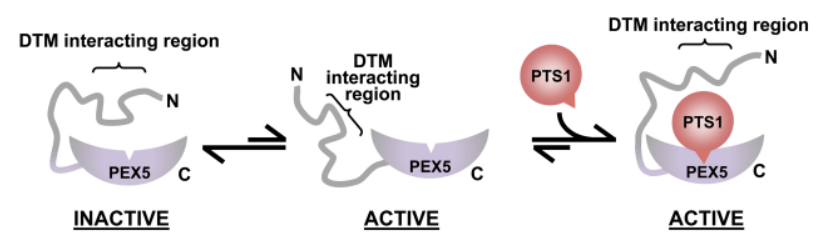

Figure 1 


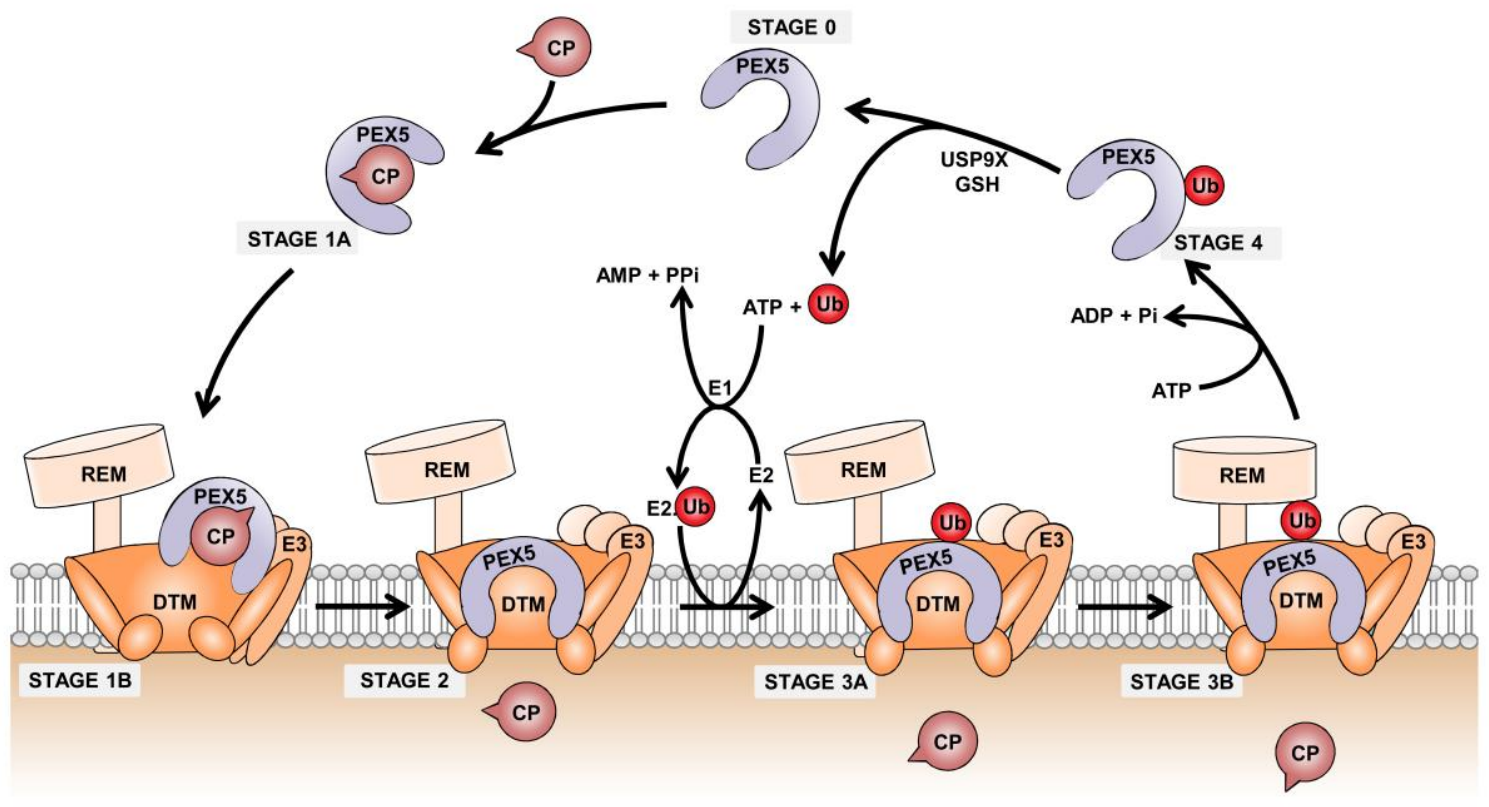

Figure 2 